\title{
USOS E POTENCIAL MADEIREIRO DO JACATIRÃO-AÇU (Miconia cinnamomifolia (DE CANDOLLE) NAUDIN) NO LITORAL DE SANTA CATARINA
}

\author{
Cristiano Schuch ${ }^{1}$, Alexandre Siminski ${ }^{2}$, Alfredo Celso Fantini ${ }^{3}$ \\ ${ }^{1}$ Eng. Agrônomo, Núcleo de Pesquisas em Florestas Tropicais, UFSC, Florianópolis, SC, Brasil - cristiano.schuch@ig.com.br \\ ${ }^{2}$ Eng. Agrônomo, M.Sc., Núcleo de Pesquisas em Florestas Tropicais, UFSC, Florianópolis, SC, Brasil - alesiminski@yahoo.com.br \\ ${ }^{3}$ Eng. Agrônomo, Dr., Núcleo de Pesquisas em Florestas Tropicais, UFSC, Florianópolis, SC, Brasil - afantini@cca.ufsc.br
}

Recebido para publicação: 22/10/2007 - Aceito para publicação: 22/04/2008

\begin{abstract}
Resumo
Este trabalho teve como objetivos avaliar o potencial madeireiro e o rendimento de madeira do jacatirão-açu (Miconia cinnamomifolia (De Candolle) Naudin). Foram medidas 36 árvores para as estimativas de fator de forma comercial (ffc) e fator de casca (fc). Foi também estimado o rendimento de madeira serrada comercial a partir do desdobro de oito toras. A aceitação da espécie no mercado madeireiro da região foi avaliada através de 30 entrevistas semi-estruturadas em serrarias e fábricas de móveis e esquadrias. Dos estabelecimentos visitados, $70 \%$ manifestaram a aceitação em trabalhar com M. cinnamomifolia. Entre os usos da madeira, destacou-se o emprego na construção civil, com um valor pago para a madeira semelhante ao eucalipto. Através dos valores obtidos do ffc $(0,92)$ e fc $(0,91)$, foi estabelecida a equação Volume comercial $=0,000462 . \mathrm{DAP}^{2}+0,00418 \cdot \mathrm{Hc}\left(\mathrm{R}^{2} 0,97\right)$ para o cálculo do volume sólido de madeira. O rendimento no desdobro foi de $42 \%$, e adicionalmente houve o aproveitamento de $25 \%$ dos resíduos.

Palavras-chave: Potencial madeireiro; rendimento de madeira; fator de forma.
\end{abstract}

\section{Abstract}

Uses and lumber potential of jacatirão-açú (Miconia cinnamomifolia (De Candolle) Naudin) in the atlantic coast region of Santa Catarina State, Brazil. This work aimed at evaluating the potential and yield of Miconia cinnamomifolia for lumber production. They were measured 36 trees to estimate the commercial form factor (ffc) and the bark factor (fc). They were also estimated the sawn timber yield from eight logs. The acceptance of the timber of this species in the local market was evaluated through the application of 30 semi-structured interviews to owners of sawmills and furniture and frame factories. Among them, $70 \%$ would accept the timber of M. cinnamomifolia in their business. Among the main uses listed for the timber, building material is the most important one, for which the market price is equivalent to the price of Eucalyptus timber. A volume equation (Commercial Volume $=0.000462 . \mathrm{DAP}^{2}+0.00418 . \mathrm{Hc},\left(\mathrm{R}^{2} 0.97\right)$ was adjusted to estimate the solid volume of timber. The sawing yield was $42 \%$, and there was also an additional utilization of $25 \%$ of the residues.

Keywords: Lumber potential; sawn timber yield; factor form.

\section{INTRODUÇ̃̃o}

As florestas tropicais primárias estão sendo dizimadas a um ritmo acelerado (JOHNS 1997), enquanto a demanda por madeiras tropicais aumenta continuamente (ABRAMOVITZ; MATTON, 1999). Algumas conseqüências principais emergem desses fatos: a) espera-se uma crescente pressão sobre os remanescentes dessas florestas nativas, no Brasil, especialmente na região amazônica; b) os remanescentes florestais se constituirão principalmente de florestas secundárias, que poderão se tornar grandes fornecedores de madeira (BAWA; SEIDLER, 1998) e de outros produtos florestais nãomadeiráveis (FANTINI, 1999).

Grande parte das florestas remanescentes hoje no estado de Santa Catariana são formações florestais secundárias. Essas formações são vistas, de forma geral, como de pouco valor para o propósito de produção de madeira, percepção muito natural considerando-se que a região era, até há pouco tempo, 
abundante em espécies produtoras de madeiras nobres. Segundo dados de Bet (1997), a exploração de florestas nativas chegou a representar 30\% do PIB do estado de Santa Catarina no ano de 1946.

$\mathrm{O}$ valor de mercado da madeira de espécies presentes nas formações secundárias provavelmente nunca se realizou porque, por muito tempo, houve suficiente suprimento de "madeiras-de-lei" alimentado pelo rápido processo de desmatamento em toda a região e também porque, após o esgotamento destas, a oferta de madeiras com baixo preço vindas da Amazônia e a introdução de exóticas cobriu a demanda regional (FANTINI; SIMINSKI, 2007). Atualmente, $80 \%$ da matéria-prima florestal no estado é oriunda de plantios homogêneos de espécies exóticas (ABIMICI, 2004).

A rápida disseminação do uso de espécies dos gêneros Pinus e Eucalyptus em projetos de reflorestamento para fins comerciais não é surpreendente se consideradas as características dessas espécies, especialmente os fantásticos incrementos em volume de madeira alcançados, em parte devidos ao sucesso de programas de melhoramento genético que sofreram. O que é surpreendente é que as centenas de espécies nativas com grande potencial para substituí-las para muitos usos, com significativas vantagens do ponto de vista ambiental, não têm recebido a mesma atenção.

Nas formações secundárias dos estados de Santa Catarina e do Paraná, o jacatirão-açu (Miconia cinnamomifolia (De Candolle) Naudin) é uma das principais espécies arbóreas dominantes. A combinação da grande freqüência de associações denominadas Miconietum (KLEIN, 1980) com a grande densidade de indivíduos dessa espécie nessas associações resulta em um fabuloso estoque de madeira, grande parte já em idade de exploração, mas que não tem merecido a devida atenção. A espécie possui grande potencial para manejo visando o incremento da renda dos agricultores da região através da produção de madeira.

Muitos aspectos da ecologia da espécie em florestas secundárias da região já são bem conhecidos (FANTINI; SIMINSKI, 2005). Entretanto, estudos adicionais da dinâmica do processo de sucessão das formações florestais secundárias, principalmente após a sua exploração, ainda são pouco comuns. Também são escassas as informações sobre o potencial de mercado de seus produtos, particularmente a madeira. Novos usos da madeira, bem como novas tecnologias de processamento de madeira de pequenas dimensões, podem aumentar significativamente o aproveitamento do volume de jacatirão-açu estocado nas nossas florestas secundárias. Entretanto, é importante também resgatar os usos tradicionais da madeira do jacatirão-açu, não somente visando a comercialização da sua madeira, mas também o seu uso nas propriedades dos agricultores.

Assim, este trabalho tem como objetivo avaliar o potencial de aproveitamento madeireiro de Miconia cinnamomifolia, estimando o rendimento de madeira serrada comercial e a aceitação da espécie no mercado madeireiro da região.

\section{MATERIAIS E MÉTODOS}

\section{Descrição da espécie}

M. cinnamomifolia é uma árvore perenifólia da família das Melastomatáceas, comumente de 15 a 20 metros de altura, de fuste reto, com diâmetro à altura do peito de $30 \mathrm{a} 40 \mathrm{~cm}$. Sua copa é tipicamente arredondada, de coloração verde clara. Espécie é típica de clareiras, com grande capacidade para se tornar uma pioneira antrópica e de formar densos aglomerados denominados Miconietum, apresentando longevidade de 30 a 50 anos (REITZ et al., 1978).

Ocorre da Bahia a Santa Catarina, em altitudes que variam de 600 metros até o nível do mar. Espécie característica da Floresta Ombrófila Densa (Floresta Atlântica), é encontrada nas formações Baixo-Montana e Submontana (KLEIN, 1979). Também pode ocorrer na Floresta Estacional Semidecidual (Minas Gerais) e na restinga (CARVALHO, 2003).

A madeira é moderadamente pesada, esbranquiçada ou amarelada, com alburno e cerne indistintos, dura, leve e macia para pregar. Apresenta boa durabilidade natural, contudo não é resistente à umidade e ao ataque de cupins (REITZ et al., 1978). A densidade da madeira varia de 0,70 a $0,76{\mathrm{~g} . \mathrm{cm}^{-3}}^{-3}$ a $12 \%$ de umidade, com massa específica de $0,58{\mathrm{~g} . \mathrm{cm}^{-3}}^{-}$(CARVALHO, 2003).

\section{Coleta de dados}

O estudo foi realizado na região da Grande Florianópolis, Santa Catarina, onde predomina a Floresta Ombrófila Densa e onde ocorrem densos agrupamentos do tipo Miconietum. O trabalho foi desenvolvido em três etapas: 
- $1^{\circ}$ Etapa: Foram entrevistadas 30 empresários, entre madeireiros e proprietários de serrarias, utilizando entrevistas semi-estruturadas (MINAYO, 2000), para a coleta de informações sobre qualidade da madeira, emprego, aproveitamento das árvores, rendimento, preço potencial e aceitação da madeira. O número representa $18 \%$ dos estabelecimentos da região $(\mathrm{n}=167)$. Assim, o erro admissível da amostragem foi de 17\%, segundo o método de cálculo de Barbetta (2006).

- $2^{\circ}$ Etapa: Foi realizado o levantamento de 36 indivíduos de $M$. cinnamomifolia, em que foram mensurados, com auxílio de escadas, os diâmetros a cada metro até a altura de 7 metros, para a obtenção da cubagem rigorosa. $\mathrm{O}$ fator de forma comercial de cada árvore foi obtido da relação entre o volume comercial (sólido), através da metodologia de Smalian, o volume estimado a partir do DAP (diâmetro à altura do peito) e da altura total. Já o fator de casca foi obtido pela relação entre o DAP com casca e o DAP sem casca. Foram realizadas análises de regressão para identificar e avaliar as possíveis relações existentes entre as variáveis DAP, altura comercial e volume sólido de madeira. Os modelos obtidos foram representados na forma de equação, com o objetivo de explicar e/ou prever os comportamentos que relacionam as variáveis. A avaliação dos modelos foi feita através do coeficiente de determinação $\left(\mathrm{R}^{2}\right)$, teste $\mathrm{F}$ da análise da variância do modelo e t-teste para os parâmetros do modelo (p).

- $3^{\circ}$ Etapa: Foi realizado um levantamento do aproveitamento de madeira em uma serraria da região, onde foram avaliadas oito toras sem casca de jacatirão-açu. Essas árvores eram originárias de corte autorizado pela Fundação Estadual do Meio Ambiente (Fatma), dentro da categoria de uso eventual de material lenhoso. As toras foram marcadas a cada 1 metro e, quando a última fração apresentava menos de 1 metro, registrava-se o valor correspondente. Após as medições, foram estimados os volumes brutos de madeira $\left(\mathrm{m}^{3}\right)$, através da fórmula de Smalian, e o fator de forma da tora (fft), pela relação entre o volume bruto e o volume cilíndrico. Cada tora foi identificada individualmente para se realizar o controle do rendimento em banca, e submetida ao processo de desdobro (serragem). No processo de desdobro, as dimensões das peças obtidas foram definidas de acordo com as características de cada tora, que variavam em diâmetro, conicidade e comprimento. Após o desdobro da tora, o produto resultante foi separado, sendo realizada a medição, com o auxilio de trena e paquímetro, e posteriormente a cubagem de cada peça do material processado. A cubagem foi obtida com seções de formatos quadrados e retangulares, o que facilitou o trabalho e aumentou a acuracidade na obtenção do volume do material processado. Com a soma das cubagens, obteve-se o volume em $\mathrm{m}^{3}$.tora ${ }^{-1}$, e a partir deste, foi estimado o rendimento (\%). Foi estimado também o aproveitamento de resíduos no processo de refilagem.

\section{RESULTADOS E DISCUSSÃO}

\section{Uso e potencialidade de Miconia cinnamomifolia}

Todos os estabelecimentos madeireiros (serrarias e madeireiras) levantados confirmaram o aproveitamento de madeiras nativas exploradas na região até o final da década de 1980 . Atualmente, $46 \%$ dos estabelecimentos madeireiros levantados trabalham apenas com madeiras de espécies exóticas (dos gêneros Pinus e Eucalyptus), outros $46 \%$ trabalham com madeira de espécies oriundas da região Norte do país e o restante $(8 \%)$ com ambas as origens. Apesar disso, $70 \%$ dos estabelecimentos manifestaram a aceitação em trabalhar com espécies nativas de florestas secundárias, caso fosse estabelecida uma política com esse objetivo. Dentre as espécies de maior interesse, foram apontadas Miconia cinnamomifolia (jacatirão-açu), Hyeronyma alchorneoides (licurana) e espécies do gênero Nectandra spp. (o grupo das canelas-amarelas).

Entre os usos mencionados para a madeira do jacatirão-açu, destacaram-se o emprego na construção civil, através de ripas, sarrafos, tabuado em geral, estacas e alinhamentos de telhado. A qualidade da madeira foi destacada por todos os entrevistados, e segundo suas experiências, o corte da madeira deve ser realizado no inverno, para evitar $\mathrm{o}$ ataque à madeira por brocas e cupins.

Segundo os entrevistados, jacatirão-açu também possui um excelente potencial de aproveitamento na serraria, pela própria característica de crescimento retilíneo (monopodial) do tronco, com a primeira ramificação normalmente acima dos 6 metros, com um aproveitamento mínimo de duas toras por árvore (3 metros). Além disso, as ramificações possuem grande potencial para serem usadas na conversão em carvão vegetal e lenha. 
Em termos econômicos, o valor pago pela tora em pé (no mato) seria equivalente ao do eucalipto, que na região é de aproximadamente $\mathrm{R} \$ 150,00$ por metro cúbico. Após o beneficiamento, esse valor passaria para cerca de $\mathrm{R} \$ 380,00 / \mathrm{m}^{3}$, chegando a um máximo de $\mathrm{R} \$ 700,00 / \mathrm{m}^{3}$ para as tábuas serradas ( $>25 \mathrm{~cm}$ de largura). Adicionalmente, os subprodutos do beneficiamento (refilos) são comercializados a um valor médio de $\mathrm{R} \$ 17,00 / \mathrm{m}^{3}$.

De todos os estabelecimentos pesquisados, 22 (73\%) acreditam que a madeira do jacatirão-açu, assim como das outras espécies, teriam mercado garantido caso existisse disponibilidade de matériaprima (árvores com diâmetro à altura do peito maior ou igual a $20 \mathrm{~cm}$ ), podendo inclusive tomar uma significativa fatia do mercado. Adicionalmente, $43 \%$ dos estabelecimentos têm interesse em participar de discussões junto aos órgãos de fiscalização e universidades para discutir a utilização de espécies madeireiras das formações florestais secundárias.

\section{Rendimento comercial da árvore}

Foram estudados 36 indivíduos de $M$. cinnamomifolia com DAP entre 10 e $38 \mathrm{~cm}$, e média de $20,7 \mathrm{~cm}$. O fator de forma comercial (ffc) estimado da espécie foi de 0,92, considerando-se um diâmetro final da tora de até $10 \mathrm{~cm}$ (Tabela 1). O fator de casca (fc) estimado foi de 0,91 .

Tabela 1. Fator de forma comercial (ffc) para Miconia cinnamomifolia em duas diferentes classes de diâmetro.

Table1. Commercial form factor (ffc) for Miconia cinnamomifolia for two diametric classes.

\begin{tabular}{lc}
\hline Classe de diâmetro $(\mathbf{c m})$ & Fator de forma comercial $(\mathbf{f f c}) *$ \\
\hline 10 a $20(\mathrm{n}=19)$ & $0,93 \mathrm{a}$ \\
20 a $40(\mathrm{n}=17)$ & $0,91 \mathrm{a}$ \\
\hline Média & 0,92 \\
\hline * Os valores de ffc não diferiram entre si pelo teste t-student $(\mathrm{p}>0,05) ;{ }^{*}$ The ffc value aren't \\
different by t-student test $(\mathrm{p}>0,05)$.
\end{tabular}

Dados da literatura são bastante variados, mas normalmente os maiores valores de fator de forma estão diretamente relacionados com o maior valor do DAP. Por exemplo, Tonini et al. (2003) encontraram valores de fator de forma variando entre 0,36 e 0,88 para diâmetros entre $2,1 \mathrm{~cm}$ e $32 \mathrm{~cm}$, respectivamente, para Nectandra megapotamica. Valores crescentes também foram encontrados por Durlo; Denardi (1998) para Cabralea canjerana, por Schneider et al. (2000) para Helietta apiculata, por Spathelf et al. (2001) para Ilex brevicuspis, Erythoxylum deciduum, Cytharexylum montevidense e Rapanea ferruginea. Apesar de não significativa, a tendência apresentada nos dados de reduzir o fator de forma na classe de maior diâmetro pode estar associada a uma maior dilatação do fuste próximo ao solo, fazendo com que a primeira tora assuma a forma parecida com a de um neilóide, como definiu Patterson et al. (1993).

A partir dos dados do fator de forma comercial e do fator de casca levantados foi possível estabelecer um modelo de regressão para estimar o volume comercial da árvore através da mensuração do DAP e da altura comercial. Segundo Machado et al. (2002), o procedimento mais comum utilizado na estimativa de volumes por árvore é o emprego de equações em que o volume constitui a variável dependente, estando as variáveis independentes comumente representadas pelo DAP e pela altura total ou altura comercial.

O modelo que obteve o melhor ajuste foi o de regressão múltipla $\left(\mathrm{R}^{2}=0,97\right)$. Tanto o modelo quanto os coeficientes foram significativos ao nível de $5 \%$ de probabilidade de erro. Para o cálculo do volume comercial, o modelo selecionado foi:

Volume comercial $=0,000462 \mathrm{DA} \mathrm{P}^{2}+0,00418 \mathrm{Hc}$

Em que: Volume comercial $=$ Volume sólido de madeira $\left(\mathrm{m}^{3}\right)$.

$\mathrm{DAP}=$ Diâmetro à altura do peito $(\mathrm{cm})$.

$\mathrm{Hc}=$ Altura comercial em metros.

\section{Rendimento comercial da tora}

Foi acompanhado o beneficiamento de oito toras de $M$. cinnamomifolia, com diâmetro médio de $32 \mathrm{~cm}$ e 3,27 metros de comprimento. A tabela 2 apresenta os dados referentes ao rendimento das toras medidas. $\mathrm{O}$ fator de forma da tora (fft) foi de 0,85 , enquanto que o rendimento médio em banca de 
aproximadamente 42\%, chegando até um valor máximo de 72,7\% (Tabela 2). O baixo valor de rendimento da tora número 5 esteve associado a defeitos com rachaduras e ataques por agentes xilófagos, provocando a redução no aproveitamento em madeira serrada.

Tabela 2. Percentual do aproveitamento do desdobro de Miconia cinnamomifolia.

Table 2. Sawing yield from Miconia cinnamomifolia.

\begin{tabular}{|c|c|c|c|c|c|c|c|}
\hline Tora & $\begin{array}{l}\text { Diâmetro } \\
\text { médio } \\
\text { (m) }\end{array}$ & $\begin{array}{c}\text { Compr. } \\
\text { tora } \\
(\mathbf{m})\end{array}$ & $\begin{array}{c}\text { Volume } \\
\text { cilíndrico } \\
\left(\mathbf{m}^{\mathbf{3}}\right)\end{array}$ & $\begin{array}{c}\text { Volume } \\
\text { bruto } \\
\left(\mathbf{m}^{\mathbf{3}}\right)\end{array}$ & $\begin{array}{c}\text { Fator de } \\
\text { forma } \\
\text { da tora } \\
\text { (fft) }\end{array}$ & $\begin{array}{c}\text { Volume } \\
\text { de madeira } \\
\text { em banca } \\
\left(\mathbf{m}^{3}\right) \\
\end{array}$ & $\begin{array}{c}\text { Rendimento } \\
\text { médio } \\
(\%)\end{array}$ \\
\hline 1 & 0,32 & 4,00 & 0,32 & 0,30 & 0,93 & 0,14 & 46,6 \\
\hline 2 & 0,32 & 3,27 & 0,27 & 0,22 & 0,82 & 0,10 & 45,4 \\
\hline 3 & 0,39 & 2,33 & 0,27 & 0,25 & 0,89 & 0,12 & 48,0 \\
\hline 4 & 0,35 & 3,18 & 0,30 & 0,16 & 0,52 & 0,06 & 37,5 \\
\hline 5 & 0,37 & 2,93 & 0,31 & 0,28 & 0,88 & 0,05 & 18,0 \\
\hline 6 & 0,23 & 2,80 & 0,12 & 0,11 & 0,95 & 0,08 & 72,7 \\
\hline 7 & 0,35 & 4,34 & 0,42 & 0,44 & 1,00 & 0,16 & 36,4 \\
\hline 8 & 0,26 & 3,27 & 0,18 & 0,14 & 0,75 & 0,04 & 28,6 \\
\hline Média & 0,32 & 3,27 & 0,27 & 0,24 & 0,85 & 0,09 & 41,7 \\
\hline
\end{tabular}

O alto valor do fator de forma das toras (fft) obtido para alguns exemplares pode estar associado à metodologia empregada para a estimativa do volume bruto, através da fórmula de Smalian. De acordo com Machado et al. (2006), todos os métodos de cubagem através de expressões aproximativas apresentaram tendência a superestimar o volume verdadeiro. Segundo o autor, o método de Smalian apresenta tendência a superestimar os volumes da porção inferior do fuste e o volume de todo o fuste, sendo mais intensa quanto maior for a secção.

Os dados de rendimento médio obtidos no processo de desdobro das toras em tábuas de Miconia cinnamomifolia se aproximam dos níveis de utilização nacionais, segundo Polzl et al. (2003), entre 40\% e 45\%. Os valores também estão próximos aos encontrados por Biasi; Rocha (2007) em levantamento de três espécies nativas da região amazônica: Mezilaurus itauba (itaúba) apresentou rendimento de 50\%, Erisma uncinatum (cedrinho) 57\% e Qualea albiflora (cambará) 59\%, para diâmetros de até $40 \mathrm{~cm}$.

O valor obtido na tora número $6(72,7 \%)$ mostra-se como uma exceção, estando relacionado ao tamanho reduzido da tora associado ao seu alto valor do fator de forma da tora $(0,95)$. Segundo Mendes et al. (2004), considerando uma tora cilíndrica, e desejando-se retirar apenas um bloco central, o rendimento médio corresponderia a, no máximo, 63,6\%. Rendimentos superiores a $70 \%$ normalmente estão associados a espécies de coníferas, como os resultados obtidos por Valério et al. (2007) em toras sem casca de Araucaria angustifolia.

Além do aproveitamento em banca, considerado o mais nobre, foi possível ainda aproveitar $25 \%$ do material restante em peças de madeira de menor dimensão (até $10 \mathrm{~cm}$ ). Adicionalmente, todo material oriundo do processo de refilagem pode ser comercializado para a produção de carvão. Mendes et al. (2004) estimam que, ao se desdobrar uma tora, a geração de resíduos é inevitável, sendo que o volume e tipos de fragmentos gerados são dependentes de vários fatores, mas, em média, constituem-se em $7 \%$ de casca, $10 \%$ de serragem e $28 \%$ de pedaços.

\section{CONCLUSÕES}

De acordo com os resultados obtidos, pode-se concluir que:

- Existe um mercado potencial e interesse por parte das serrarias e madeireiras em trabalhar com espécies nativas, entre elas a Miconia cinnamomifolia.

- A espécie reúne características que permitem um bom aproveitamento da árvore, apresentando, até a altura comercial, padrão semelhante a outras espécies nativas comercializadas.

- É possível estimar com boa precisão o volume comercial de madeira, através dos dados do DAP e da Hc.

- $\quad$ O rendimento da tora está dentro dos padrões gerais para espécies nativas, podendo chegar até um valor máximo de 72,7\%. Adicionalmente, praticamente todos os resíduos podem ser aproveitados. 
- A exploração dessa e de muitas outras espécies de crescimento rápido das formações florestais da Mata Atlântica traria como benefício direto uma nova e imediata fonte de renda para os agricultores da região, e, principalmente, promoveria a conservação dos remanescentes florestais pelos agricultores, que passariam a vê-los como um valioso recurso.

\section{REFERÊNCIAS}

ASSOCIAÇÃO BRASILEIRA DA INDÚSTRIA DE MADEIRA PROCESSADA MECANICAMENTE (ABIMCI). Setor do processamento mecanico da madeira em Santa Catarina. [S.1.]: ABIMICI, 2004, $33 \mathrm{p}$.

ABRAMOVITZ, J. N.; MATTON, A. T. Reorienting the forest products economy. In: ABRAMOVITZ, J. N. et al. State of the World. New York: Norton, 1999. p.60-77.

BARBETTA, P. A. Estatística aplicada as Ciências Sociais. Florianópolis: Ed. da UFSC, 2006.315 p.

BAWA, K.; SEIDLER, S. Natural forest management and conservation of biodiversity in tropical forests. Conservation Biology,Boston, v. 12, n. 1, p. 45-50, 1998.

BET, M. Análise da introdução do componente florestal em sistemas de produção representativos da região de Florianópolis, Santa Catarina. Florianópolis: Editora da UFSC, 1997. 134 p.

BIASI, C. P.; ROCHA, M. P. Rendimento em madeira serrada e quantificação de resíduos para três espécies tropicais. Floresta, Curitiba, v. 37, n. 1, p. 95-108, 2007.

CARVALHO, P. E. R. Espécies arbóreas brasileiras. Brasília: Embrapa Informação Tecnológica; Colombo-PR: Embrapa Florestas, 2003. v. 1.

DURLO, M. A.; DENARDI, L. Morfometria de Cabralea canjerana em mata secundária nativa do Rio Grande do Sul. Ciência Florestal, Santa Maria, v. 8, n. 1.p. 55-66, 1998.

FANTINI, A. C. Palm Heart (Euterpe edulis) Production and Management in the Brazilian Mata Atlântica. 127 p. Dissertação (Doutorado) - University of Wisconsin, Madison,1999.

FANTINI, A. C.; SIMINSKI, A. Recuperação natural da vegetação após uso agrícola da terra no litoral de Santa Catarina. In: SIMPÓSIO NACIONAL E CONGRESSO LATINO AMERICANO DE RECUPERAÇÃO DE ÁREAS DEGRADADAS, 6., 2005, Curitiba/PR. Anais do... Curitiba: SOBRADE, 2005. p. 147-155.

FANTINI, A. C.; SIMINSKI, A. De agricultor à agricultor silvicultor: Um novo paradigma para a conservação e uso de recursos florestais no sul do Brasil. Agropecuária Catarinense, Florianópolis, v. 20, p. 16-18, 2007.

JOHNS, A. G. Timber Production and Biodiversity Conservation in Tropical Rain Forests. Cambridge: Cambridge University Press, 1997. 225 p.

KLEIN, R. M. Ecologia da Flora e Vegetação do Vale do Itajaí. Sellowia, Itajaí, v. 31, n. 31, p.1-164, 1979.

KLEIN, R. M. Ecologia da Flora e Vegetação do Vale do Itajaí. Sellowia, Itajaí, v. 32, n. 32, p.164-369. nov. 1980.

MACHADO, S. A.; CONCEIÇÃO, M. B.; FIGUEIREDO, D. J. Modelagem do volume individual para diferentes idades e regimes de desbaste em plantações de Pinus oocarpa. Ciências Exatas e Naturais, Curitiba, v. 4, n. 2, p. 185- 196, 2002.

MACHADO, S. A.; TÉO, S. J.; URBANO, E.; FIGURA, M. A.; SILVA, C. R. Comparação de métodos de cubagem absolutos com o volume obtido pelo xilômetro para bracatinga (Mimosa scabrella Bentham) Cerne, Lavras, v. 12, n. 3, p. 239-253, jul./set. 2006.

MENDES, L. M.; RABELO, G. F.; TRUGILHO, P. F.; MORI, F. A. Energia a partir de resíduos florestais. Revista da Madeira, Curitiba, Edição 85, ano 14, novembro de 2004. 
MINAYO, M. C. S. O Desafio do Conhecimento: Pesquisa Qualitativa em Saúde. São Paulo: HUCITEC - ABRASCO, 2000. 82 p.

PATTERSON, D. W.; WIANT JUNIOR, H. V.; WOOD, G. B. Errors in estimating the volume of butt logs. Forest Products Journal, Morgantown, v. 43, n. 3, p. 41-44, mar.1993.

POLZL, W. B.; DOS SANTOS, A. J.; TIMOFEICZYK JR, R.; POLZL, P. K. Cadeia produtiva do processamento mecânico da madeira - segmento da madeira serrada no estado do Paraná. Floresta, Curitiba, v. 33, n. 2, p. 127-134, 2003.

REITZ, R.; KLEIN, R. M.; REIS, A. Projeto madeira de Santa Catarina. Sellowia, Itajaí, n. 28/30, p.3$320,1978$.

SCHNEIDER, P. S. P.; SCHEREN, L. W.; FLEIG, F. D. Crescimento da canela de veado Helietta apiculata Benth., na depressão central do Estado do Rio Grande do Sul. In: SIMPOSIO LATINOAMERICANO SOBRE MANEJO FLORESTAL, 1., 2000, Santa Maria. Anais... Santa Maria : UFSM, CCR, Programa de Pós-graduação em Engenharia Florestal, 2000. p.177-189.

SPATHELF, P.; BERGER, R.; VACCARO, S.; TONINI, H.; BORSOI, G. A. Crescimento de espécies nativas de uma floresta estacional decidual/ombrófila mista do Rio Grande do Sul. Ciência Florestal, Santa Maria, RS, v. 11, n. 2, p. 103-119, 2001.

TONINI, H.; FINGER, C. A. G.; SCHNEIDER, P. R. O crescimento da Nectandra megapotamica Mez., em floresta nativa na depressão central do Estado do Rio Grande do Sul. Ciência Rural, Santa Maria, RS, v. 33, n. 1, jan-fev, p85-90, 2003.

VALÉRIO, A. F.; WATZLAWICK, L. F.; SANTOS, R. T.; BRANDELERO, C.; KOEHLER, H. S. Quantificação de resíduos e rendimento no desdobro de Araucaria angustifolia (Bertol.) O. Kuntze. Floresta, Curitiba, v. 37, n. 3, set./dez. 2007. 